\title{
Covid-19: The US state copying a global health template for contact tracing success
}

\author{
Contact tracing is widely considered to be key to ending the pandemic. Tinker Ready visits the \\ pioneering Massachusetts effort taking a leaf out of west Africa's book
}

Tinker Ready freelance journalist

Cambridge, MA, USA

When the governor of Massachusetts announced the state's ambitious covid-19 contract tracing programme at a televised briefing last month, two doctors stood in the wings. They were from the international health aid group Partners in Health (PIH), which has played a key role in containing outbreaks of Ebola in west Africa and tuberculosis in Peru. The group's well tested methods for ending epidemics in these places relied on identifying, calling, and quarantining those who had been in contact with infected patients.

While Google, Apple, and university researchers discuss computer contact tracing possibilities with the federal government, Boston based PIH has been part of a partnership with several state agencies that has hired students, public health professionals, and lay people who have started making phone calls.

Across the United States, other state and local governments are also putting contact tracing in place, including in San Francisco and hard-hit New York, New Jersey, and Connecticut. But some states, including a few that are starting to lift limits on restaurants and other public services and events, have not, even though many US public health experts say that loosening up restrictions should not occur until contact tracing is in place.

With so much interest in the Massachusetts model, the Community Tracing Collaborative-comprising state employees and PIH staff-held a webinar on 27 April to describe the details of their plan. "Every state is going to have its own complexity." Jim Kim, one of the physician founders of PIH and former head of the World Bank, said at the end of the video presentation. "The key is to get started and get started as quickly as you can."

\section{People power}

The test-track-isolate plan is an expensive, unwieldy undertaking-familiar words to Kim and the PIH team, who are undaunted. "We've done this in much more difficult settings with much more difficult problems - for example, treating AIDS in Africa," he said.
Contact tracing isn't cheap. Massachusetts's move to put in place its contact tracing programme is budgeted at $\$ 44 \mathrm{~m}(£ 36 \mathrm{~m}$; $€ 41 \mathrm{~m})$. The estimated national cost is $\$ 3.6 \mathrm{bn} .{ }^{1}$ Whatever the method, contract tracing will require a "massive" expansion of the public health workforce-100 000 to 300000 tracers-said Crystal Watson of the Johns Hopkins Bloomberg School of Public Health. ${ }^{2}$

Overburdened local health departments, used to tracking sexually transmitted disease cases, are waiting for tracing teams from the Centers for Disease Control and Prevention to help them. Schools of public health and medicine are sending out student volunteers. Graduate students had been running the programme in Massachusetts. Now, they're handing it over to teams hired and trained by PIH and based in local health departments.

"We don't have that many tools to respond to this pandemic, but the two tools that we have-testing and contract tracing — can be very effective," Watson said. "We have seen this implemented in other countries to great effect."

Joia Mukherjee, the chief medical officer of PIH, was one of the doctors present at the announcement of the PIH-government partnership in early April. She said that the success of PIH's contact tracing in a 2014 Ebola outbreak in Tonkolili,Sierra Leone, shows the strength of the approach. If they can do it there, they can do it in Massachusetts, she said. "Is it too late? It cannot be too late."

At the time of the announcement in early April, only about 9000 people had tested positive in Massachusetts. By the time the contact tracing programme got started in late April, the number had reached 68000 , and there were more than 4000 deaths. As at 12 May, there were 79332 cases and 5141 deaths.

By late April, 163 of those cases were in Watertown, Massachusetts, a small city close to Boston. Pawandeep Kaur, a clinical researcher at the Boston University School of Public Health was recruited to help there through a partnership between 
12 Massachusetts schools of public health and more than 300 local health departments. Kaur, who is also working on her doctorate, spent much of April helping the Waterdown Department of Health interview patients and track down contacts.

\section{The reality}

Watertown, a middle income city of 32000 people, had a staff of two nurses to do all its contract tracing. Now Kaur and others are part of a massive, remote call centre. Tracers use their own phones and work from home. Although Kaur studied tuberculosis, she had never done contract tracing before.

"The first call takes you longer because you're not in the flow of things," Kaur told The BMJ. "That was a little bit nerve racking — am I giving them all the information? Am I asking all the questions?" She asks patients to think back to those with whom they've been in touch since two days before developing symptoms. Contacts include anyone they've spent more than 15 minutes with and anyone who was less than six feet away.

"The grocery store worker who you interface with for a minute doesn't count," she said. "It's tricky." The tracers are instructed not to give out detailed health advice. They can refer callers to a resource coordinator who can help with a food delivery or housing for those unable to quarantine in a crowded apartment.

"Most people are like: 'Here's all the information. Here are all the people. Here's where I work.' They get it. I think it's all a matter of how we explain it to them," says Kaur. But not everyone wants to share their contact information, and there is nothing the tracers can do about that.

The search is on for mobile apps that will automate some elements of contract tracing. Apple and Google are working together on a tool designed to alert contacts while also protecting patients' privacy by using Bluetooth instead of GPS. Several states and countries are developing or adopting their own apps-there is already a covid-19 apps Wikipedia page and the
US Centers for Disease Control and Prevention has put out guidance for developers. But privacy advocates have expressed concerns about the recording and use of geographical information.

Watson said that the apps need to find a balance between privacy and producing useful information for public health efforts. Even when they do, they won't replace human contact tracers. "The reasons they need to get in touch with them is not just to identify them and to tell them to quarantine," Watson said. "That can potentially be done by an app. When you ask someone to stay home for 14 days, they may need support to do that."

In Massachusetts, more than 30000 people applied for 2000 tracer jobs, which is paying $\$ 27$ an hour, more than twice the local minimum wage. Lori Freeman, head of the National Association of County and City Health Officials, told The BMJ that the US will need 100000 tracers to make the tracing programme work-the low end of the Hopkins estimate. She's concerned that in the past decade, public health programmes have shed one in four workers, but she's hopeful that public health students can fill the gap, and she's confident that US states and municipalities can build effective programmes.

"It is doable," she says. "If we have other countries doing this successfully, there's no reason why a country as well resourced as ours can't do it."

Competing interests: I have read and understood BMJ policy on declaration of interests and have no relevant interests to declare.

1 The Edmond J Safra Center for Ethics at Harvard University Roadmap to Pandemic Resilience. Massive scale testing, tracing, and supported isolation (TTSI) as the path to pandemic resilience for a free society. https://ethics.harvard.edu/files/center-for-ethics/ files/roadmaptopandemicresilience_updated_4.20.20_0.pdf

2 Johns Hopkins Bloomberg School of Public Health. Public health principles for a phased reopening during covid-19: guidance for governors. $17 \mathrm{Apr} 2020$. https://www. centerforhealthsecurity.org/our-work/pubs_archive/pubs-pdfs/2020/200417-reopeningguidance-governors.pdf

Published by the BMJ Publishing Group Limited. For permission to use (where not already granted under a licence) please go to http://group.bmj.com/group/rights-licensing/ permissions 